\title{
Long-Term Feeding of Formulas High in Linolenic Acid and Marine Oil to Very Low Birth Weight Infants: Phospholipid Fatty Acids
}

\author{
SUSAN E. CARLSON, RICHARD J. COOKE, PHILIP G. RHODES, JEANETTE M. PEEPLES, \\ SUSAN H. WERKMAN, AND ELIZABETH A. TOLLEY \\ Departments of Pediatrics, Obstetrics and Gynecology, Biochemistry, and Biostatistics and Epidemiology, \\ The University of Tennessee, Memphis, Tennessee 38163
}

\begin{abstract}
Red blood cell (RBC) phospholipids of infants fed human milk compared with formula have more arachidonic acid (AA) and docosahexanoic acid (DHA). The addition of low levels of marine oil to infant formula with 0.6 to $2.0 \% \alpha$-linolenic acid (LLA, 18:3n-3) prevented declines in DHA in formula-fed infants; however, the feeding trials were short ( 4 to $6 \mathrm{wk}$ ), LLA concentrations were low compared with current formulas (3.0 to $5.0 \%$ LLA), and the formulas were unstable. Trials with stable formulas were necessary to determine if dietary DHA could maintain phospholipid DHA after discharge from the hospital and, in fact, if it was necessary with higher intakes of LLA. The results of acute ( $4 \mathrm{wk}$ ) and extended (to $79 \mathrm{wk}$ postconception) feeding of such formulas on $\mathrm{RBC}$ and plasma phospholipid AA and DHA are reported here. Control formulas were identical to commercially available formulas. Experimental formulas differed only in the addition of small amounts of marine oil. DHA in RBC and plasma phosphatidylethanolamine (PE) declined during four weeks of feeding but not if marine oil provided DHA $(0.2 \%$ or $0.4 \%)$ and plasma phospholipid AA $(\mathrm{g} / 100 \mathrm{~g})$ decreased with time and marine oil feeding. Extended feeding with marine oil accounted for half the DHA in RBC and plasma phosphatidylethanolamine at equilibrium; however, RBC $(\mathrm{g} / 100 \mathrm{~g})$ and plasma AA $(\mathrm{g} / \mathbf{1 0 0} \mathrm{g} ; \mathrm{mg} / \mathrm{L}$ plasma) decreased progressively until late infancy and were depressed further by marine oil. We conclude that 1 ) $\mathrm{AA}$ and DHA decline in RBC and plasma phospholipids of preterm infants when only their n-6 and n-3 fatty acid precursors are consumed; and 2) marine oil can maintain cord concentrations of $\mathrm{RBC}$ phosphatidylethanolamine DHA but further reduces AA. (Pediatr Res 30: 404-412, 1991)
\end{abstract}

\section{Abbreviations}

AA, arachidonic acid

DHA, docosahexaenoic acid

EPA, eicosapentaenoic acid

$\mathrm{RBC}$, red blood cell

LLA, $\alpha$-linolenic acid

LOA, linoleic acid

PE, phosphatidylethanolamine

PC, phosphatidylcholine

PS, phosphatidylserine

PCA, postconceptional age

VLBW, very low birth weight

Received February 26, 1991; accepted July 9, 1991.

Correspondence: Susan E. Carlson, Ph.D., Newborn Center, Room 201, 853 Jefferson Avenue, Memphis, TN 38163.

Supported by the National Eye Institute (RO 1-EY08770) and Ross Laboratories, Columbus, $\mathrm{OH}$.
ANOVA, analysis of variance

When the normal accumulation of DHA $(22: 6 n-3)$ in the retina and brain is limited during development by diets deficient in the n-3 fatty acid, $\alpha$-linolenate, deficits in visual acuity (1), abnormal retinal responses to light (2-6), and impaired discrimination learning (7-9) occur in rats and primates. VLBW infants may also be at risk for inadequate accumulation of this fatty acid during development, not because of n-3-deficient diets, but because they miss the period of greatest intrauterine accretion (1012) and frequently receive diets without DHA after birth (1315). RBC DHA declines over time in VLBW infants, and the decline is diminished by human milk feeding (16), bolus administration of marine oil (17), and formulas containing ultrasonically dispersed marine oil (18). All of these feeding trials (16-18) were of short duration (4-8 wk). To maintain phospholipid DHA after discharge from the hospital and, ultimately, to determine if DHA is conditionally essential for some aspects of normal development in VLBW infants, stable, commercially prepared control and marine oil-supplemented formulas were necessary. When these became available, the two studies reported here were designed.

In both studies, infants were randomly assigned to receive formulas identical to commercially available preterm and term formulas (control) or experimental formulas differing from the control formulas only in the addition of small amounts of marine oil. Both control and experimental formulas were packaged without a product name. The first 4-wk feeding trial was designed to test the effects of two concentrations of marine oil in formula to determine the best marine oil concentration to use in an extended feeding trial. The second study, the extended feeding trial, was designed to provide data about the long-term effects of feeding $0.3 \%$ EPA and $0.2 \%$ DHA from marine oil on RBC and plasma phospholipid DHA and EPA of VLBW infants. Additionally, we were interested in the qualitative and quantitative effects of extended marine oil feeding on phospholipid AA in these infants: Short-term feeding trials with marine oil supplementation $(17,18)$ have not consistently shown effects on phospholipid AA, but EPA and DHA in marine oil are known to reduce $\mathrm{AA}$ in membrane phospholipids. Extended marine oil feeding, coupled with the known declines in AA that occur after premature birth (16), could result in clinically significant declines in AA.

Finally, formulas fed in earlier trials (16-18) contained lower levels of LLA ( 0.6 to $2.0 \%$ of total fatty acids or 0.3 to $1.0 \%$ of energy) than are currently found in infant formula (3.0 to $5.0 \%$ of total fatty acids or 1.5 to $2.5 \%$ of energy). RBC DHA in VLBW infants fed formula with 1.0 to $1.35 \%$ of energy from 
LLA did not differ from that in infants fed human milk $(19,20)$. Although this may have been due to the short duration of the studies ( 4 to $5 \mathrm{wk}$ ), it was suggested that $>2.0 \%$ of total fatty acids ( $>1.0 \%$ of energy) from LLA would permit incorporation of DHA in VLBW infants equivalent to human milk (19). The extended feeding trial addresses the effects on AA, DHA, and EPA of long-term feeding of $5.0 \%$ LLA ( $2.5 \%$ of energy) with and without the inclusion of EPA and DHA ( $0.25 \%$ energy).

\section{MATERIALS AND METHODS}

Selection of Subjects. Preterm infants (600-1270 g birth weight) were eligible for the acute feeding study (study 1) when they had tolerated preterm formulas at intakes $>462$ to $504 \mathrm{~kJ}$ $(110-120 \mathrm{kcal}) / \mathrm{kg} / \mathrm{d}$ for $5-7 \mathrm{~d}$. Infants were on room air or receiving oxygen (by oxyhood but not by mechanical ventilation) at enrollment. Informed consent was obtained before enrollment according to a protocol approved by the Institutional Review Board of The University of Tennessee, Memphis. A total of 21 infants were enrolled and randomized to receive one of three formulas (Formulas A, B, and C). Four infants were lost from the study: Two infants assigned to formula $A$ and one infant assigned to formula $B$ for necrotizing enterocolitis and one infant assigned to formula C for group B streptococcus meningitis. Table 1 contains a description of infants by formula fed in study 1. ANOVA by formula showed the groups to be statistically indistinguishable except in prior need for mechanical ventilation $(p<0.04)$.

Infants enrolled for extended follow-up (study 2) weighed between 748 and $1398 \mathrm{~g}$ at birth and were eligible for the study when they were receiving $>462 \mathrm{~kJ}(110 \mathrm{kcal}) / \mathrm{kg} / \mathrm{d}$ of a formula designed for preterm infants. Although infants in this birth weight range are at high risk for medical complications, infants selected for this study had fewer and milder medical complications than the population from which they were selected. Infants could not require mechanical ventilation at the time of enrollment, although they could be receiving oxygen via oxyhood. Only three of 67 infants were diagnosed as having chronic lung disease or bronchopulmonary dysplasia, many fewer than would be expected in this birth weight range in our nursery. Infants with intraventricular/periventricular hemorrhage > grade 2, retinopathy of prematurity $>$ stage 2 , or necrotizing enterocolitis requiring surgical intervention were not eligible for this protocol. Infants who developed these complications after enrollment were replaced. Infants of mothers who used cocaine or other street drugs during the pregnancy were also excluded from enrollment. Criteria for enrollment were designed to eliminate factors known or suspected to adversely influence growth and/or development, two of the long-term outcome variables of this study.

Seventy-nine infants were enrolled and randomized to receive either control or marine oil-supplemented formula after obtaining parental consent according to an Institutional Review Boardapproved protocol. Infants were enrolled during a $2-y$ period between November 1987 and 1989 and follow-up was completed in 1990. Ten of the 79 infants were replacements for infants who moved or failed to return for follow-up on or before 4 mo [57 wk postconception (noncompleters)]. Two additional infants from this group of 69 were excluded because they received soybased formula rather than the study formula between 4 and 6 mo. Table 1 includes a description of the 67 infants in the final study 2 group. Ventilator and total oxygen (h) were calculated by converting individual hours to log hours. The mean $\pm \mathrm{SD}$ (log hours) was calculated for each formula and reconverted to hours. All 67 infants (34 control/33 n-3 supplemented) completed follow-up through $4 \mathrm{mo}$. The data presented represent the following numbers of control and supplemented infants, respectively, at each age: $6 \mathrm{mo}, 34$ and 33; $9 \mathrm{mo}, 31$ and $31 ; 12 \mathrm{mo}$, 28 and 28.

Experimental Design. Short-term study (study 1). The objectives of this study were 1 ) to compare the acute effects of commercially prepared formulas containing two levels of marine oil on several 20- to 22-carbon n-6 and n-3 fatty acids in preterm infants and 2) to make this comparison with formulas containing $3.0 \%$ LLA ( $1.5 \%$ energy) instead of 0.6 to $2.0 \%$ LLA (approximately $0.3-1.0 \%$ energy) as fed previously (16-18). Accordingly, infants were fed one of three preterm formulas varying only in their quantity of eicosapentaenoate (EPA, 20:5n-3) and docosahexaenoate (DHA, 22:6n-3) for a period of $4 \mathrm{wk}$ : Formula A did not contain marine oil and was free of EPA and DHA; formula B contained $0.3 \%$ EPA and $0.2 \%$ DHA from marine oil; and formula $\mathrm{C}$ contained $0.7 \% \mathrm{EPA}$ and $0.4 \%$ DHA from marine oil (Table 2). None of the formulas contained AA. Blood samples were obtained at enrollment and weekly for the next $4 \mathrm{wk}$ for comparison of the effects of marine oil feeding on $\mathrm{RBC}$ and plasma phospholipid (PE, PC, and PS) and triglyceride fatty acids.

Long-term study (study 2). The objective of this study was to determine the effects of extended feeding of marine oil-containing formula on phospholipid fatty acids (RBC, plasma), growth, visual acuity, and cognitive function throughout infancy. Results of the effects of the formulas on the fatty acid composition of $\mathrm{RBC}$ and plasma phospholipids are reported. We hoped to determine the effects of prolonged feeding and marine oil supplementation on RBC phospholipid DHA, EPA, and AA ( $\mathrm{g} / 100$ $\mathrm{g}$ total fatty acids) and to observe the effects of time and marine oil supplementation on both the qualitative $(\mathrm{g} / 100 \mathrm{~g})$ and quantitative $(\mathrm{mg} / \mathrm{L})$ amounts of DHA, EPA, and AA of plasma phospholipids. Infants were randomized to receive either formula A or formula $\mathrm{B}$ during their hospitalization and were discharged from the hospital at approximately $1800 \mathrm{~g}$. At discharge they received a formula designed for term infants without or with marine oil supplementation according to their original randomization (formula A-T or formula B-T) (Table 2) until 79 wk postconception. Formula was provided free of charge in the quantities taken ad libitum by infants. Parents were counseled regularly throughout infancy to ensure that formula was truly

Table 1. Description of infants studied (mean $\pm S D$, range)

\begin{tabular}{lcccccc}
\hline & \multicolumn{3}{c}{ Study 1} & & \multicolumn{2}{c}{ Study 2 } \\
\cline { 2 - 3 } & $\begin{array}{c}\text { Formula A } \\
(n=6)\end{array}$ & $\begin{array}{c}\text { Formula B } \\
(n=6)\end{array}$ & $\begin{array}{c}\text { Formula C } \\
(n=5)\end{array}$ & $\begin{array}{c}\text { Formula A and A-T } \\
(n=34)\end{array}$ & $\begin{array}{c}\text { Formula B and B-T } \\
(n=33)\end{array}$ \\
\hline Birth wt (g) & $983 \pm 219$ & $833 \pm 164$ & $951 \pm 170$ & $1074 \pm 193$ & $1147 \pm 154$ \\
Wt at enrollment (g) & $1313 \pm 135$ & $1168 \pm 101$ & $1167 \pm 135$ & $1304 \pm 183$ & $1330 \pm 129$ \\
Age at enrollment (d) & $31 \pm 14$ & $36 \pm 13$ & $27 \pm 9$ & $25 \pm 10$ & $22 \pm 8$ \\
Maternal age (y) & $23 \pm 5$ & $28 \pm 6$ & $22 \pm 5$ & $23 \pm 6$ & $23 \pm 6$ \\
Maternal gravida & $2 \pm 1$ & $3 \pm 2$ & $2 \pm 1$ & $2.5 \pm 1.4$ & $2.3 \pm 1.1$ \\
Ventilator (h) & $24(3-181)$ & $108(16-805)$ & $7(2-26)$ & $12(0-91)$ & $(0-42)$ \\
Total oxygen (h) & $65(8-516)$ & $163(33-805)$ & $19(4-100)$ & $58(10-212)$ & $46(12-282)$ \\
Gestational age (wk) & $28 \pm 3$ & $28 \pm 2$ & $29 \pm 2$ & $29 \pm 2$ & $29 \pm 2$ \\
First formula (h) & $90 \pm 28$ & $108 \pm 24$ & $148 \pm 126$ & $78 \pm 55$ & $18 \pm 54$ \\
i.v. nutrition (d) & $16 \pm 2$ & $23 \pm 10$ & $21 \pm 8$ & & $18 \pm 9$ \\
\hline
\end{tabular}


Table 2. Formula composition ( $\mathrm{g} / 100 \mathrm{~g}$ total fatty acids)

\begin{tabular}{|c|c|c|c|c|c|}
\hline \multirow[b]{2}{*}{$\begin{array}{l}\text { Fatty } \\
\text { acid }\end{array}$} & \multicolumn{3}{|c|}{ Preterm formulas } & \multicolumn{2}{|c|}{ Term formulas } \\
\hline & $\begin{array}{c}\text { Formula } \\
\text { A }\end{array}$ & $\begin{array}{c}\text { Formula } \\
\text { B }\end{array}$ & $\begin{array}{c}\text { Formula } \\
\text { C }\end{array}$ & $\begin{array}{c}\text { Formula } \\
\text { A-T }\end{array}$ & $\begin{array}{c}\text { Formula } \\
\text { B-T }\end{array}$ \\
\hline $6: 0$ & 0.3 & 0.3 & 0.3 & 0.1 & 0.1 \\
\hline $8: 0$ & 28.8 & 28.8 & 28.0 & 2.3 & 2.2 \\
\hline $10: 0$ & 14.5 & 14.2 & 13.9 & 2.0 & 2.0 \\
\hline $12: 0$ & 10.0 & 9.7 & 9.5 & 17.2 & 16.9 \\
\hline $14: 0$ & 4.3 & 4.2 & 4.3 & 7.2 & 7.2 \\
\hline $16: 0$ & 6.3 & 6.2 & 6.5 & 9.9 & 10.0 \\
\hline $16: 1$ & 0.2 & 0.3 & 0.5 & & \\
\hline $17: 0$ & 0.1 & 0.1 & 0.1 & & \\
\hline \multicolumn{6}{|l|}{$17: 1$} \\
\hline $18: 0$ & 3.1 & 3.0 & 3.0 & 4.7 & 4.6 \\
\hline $18: 1$ & 9.9 & 9.8 & 9.9 & 17.1 & 17.0 \\
\hline $18: 2 n-6$ & 19.1 & 18.7 & 18.5 & 33.2 & 32.6 \\
\hline $20: 0$ & 0.3 & 0.3 & 0.3 & 0.6 & 0.6 \\
\hline $18: 3 n-3$ & 3.0 & 3.1 & 3.2 & 4.8 & 4.9 \\
\hline $18: 4 n-3$ & 0.1 & 0.2 & 0.3 & & 0.2 \\
\hline $22: 0$ & 0.2 & 0.2 & 0.2 & 0.3 & 0.3 \\
\hline \multicolumn{6}{|l|}{$20: 4 n-6$} \\
\hline $20: 5 n-3$ & & 0.3 & 0.7 & & 0.3 \\
\hline $24: 0$ & 0.1 & 0.1 & 0.1 & 0.1 & 0.1 \\
\hline $22: 5 n-3$ & & $\operatorname{tr}^{*}$ & 0.1 & & \\
\hline $22: 6 n-3$ & & 0.2 & 0.4 & & 0.2 \\
\hline${ }^{18} \mathrm{C} \mathrm{n} 6 / \mathrm{n} 3$ & 6.4 & 6.0 & 5.8 & 6.9 & 6.6 \\
\hline$\geq 20 \mathrm{C} \mathrm{n} 3$ & 0 & 0.5 & 1.2 & 0 & 0.5 \\
\hline
\end{tabular}

$* \mathrm{tr},<0.1 \mathrm{~g} / 100 \mathrm{~g}$ total fatty acids.

fed ad libitum and not limited by the caretaker. Nutrition counseling included advice to limit intake of energy sources other than formula through the $57 \mathrm{wk}$ appointment. Diet histories were obtained at each follow-up visit, with questions aimed at infants' typical intake of formula and other energy sources. Most infants received little but formula through 57 wk PCA; by $68 \mathrm{wk}$, all infants were consuming other foods but still consuming at least 24 ounces/d of their assigned formula (except one infant who was consuming 20 ounces/d). At 79 wk PCA, parents kept leftover formula and reported to us when it had been consumed. Infants continued to receive their designated formula for up to 4 wk beyond 79 wk PCA. Blood samples were obtained at enrollment and at regular intervals throughout infancy: term $(38 \pm 2$ wk PCA, mean \pm SD); 2 mo $(48 \pm 2$ wk PCA); 4 mo $(57 \pm 2$ wk PCA); 7 mo (68 \pm 2 wk PCA); 9 mo ( $79 \pm 2$ wk PCA); and $12 \mathrm{mo}(93 \pm 2 \mathrm{wk}$ PCA) for the purpose of comparing phospholipid fatty acid profiles as affected by time and marine oil supplementation.

Analytical methods. Blood $(1.5 \mathrm{~mL})$ was removed from the antecubital or femoral vein and anticoagulated with lithium heparin. After the plasma was removed, the erythrocytes were washed three times with $0.15 \mathrm{M} \mathrm{NaCl}$ in $1 \mathrm{mM}$ EDTA, resuspended in an equal volume of the saline-EDTA solution, and stored at $-70^{\circ} \mathrm{C}$. Samples were stored less than $7 \mathrm{~d}$ before fatty acid analysis. Total lipids were extracted from plasma and erythrocytes according to Dodge and Phillips (21) with chromatography grade solvents and washed with $0.15 \mathrm{M} \mathrm{KCl}$ according to Folch et al. (22) to remove nonlipid contaminants. PE, PS, and PC were separated on silica gel plates $(10 \times 10 \mathrm{~cm}, 0.25 \mathrm{~mm}$; Analtech, Inc., Newark, DE) for $20 \mathrm{~min}$ in chloroform-methanolacetic acid-water $(60: 30: 8.4: 4.6, \mathrm{vol} / \mathrm{vol} / \mathrm{vol} / \mathrm{vol})$, a modification of the solvent system of Zail and Pickering (23) and identified and recovered for methylation as described previously (17). Butylated hydroxytoluene $(50 \mathrm{mg} / \mathrm{L})$ was added to the methanol in the eluting solvent. In study 1 , the total lipid extract was spotted on a 10 (wide) $\times 20$ (high) $\mathrm{cm}$ plate. Triglycerides were separated from total phospholipids (24). The total phospholipids that remained at the origin were then separated as described above by a modification of the solvent system of Zail and
Pickering (23). Fatty acids in phospholipids and triglycerides were methylated according to Morrison and Smith (25) in an oxygen-free atmosphere.

Methylated fatty acids from both phospholipids and triglycerides were extracted with pentane, the solvent vaporized under nitrogen, and the samples dissolved in $10 \mu \mathrm{L}$ dichloromethane. The fatty acid methyl esters were injected onto a $30 \mathrm{~m} \times 0.25$ $\mathrm{mm}$ open tubule column with a stationary liquid phase (SP2330; Supelco, Inc., Bellefonte, PA) installed in a Varian 3300 gas chromatograph programmed for column, injector, and detector temperatures of 175,210 and $220^{\circ} \mathrm{C}$. Helium was used as the carrier gas. The column temperature was held constant for 5 min after injection then advanced at $2^{\circ} \mathrm{C} / \mathrm{min}$ to $195^{\circ} \mathrm{C}$ and held constant for an additional $5 \mathrm{~min}$. Individual peaks were integrated and identified automatically with a programmable Varian 4290 recorder/integrator. Identification of individual fatty acids was made by comparison to authentic standards and by loglinear plots of retention times of authentic standards plotted after isothermal gas liquid chromatography separations. A biologic mixture of fatty acids containing the fatty acids of interest was analyzed daily (PUFA 1; Supelco, Inc.), and other quantitative standards (NHI-C, NHI-F, NHI-C, and NHI-D; Supelco, Inc.) were analyzed periodically to check column integrity.

To determine quantitatively the amount of each fatty acid in plasma phospholipids and triglycerides, the procedures for lipid extraction, thin layer chromatography, methylation, and gas liquid chromatography were used as detailed previously but with careful attention to quantitative technique: Total lipids were extracted from $0.3 \mathrm{~mL}$ plasma, the extract reconstituted in 0.3 $\mathrm{mL}$ dichloromethane, and $0.15 \mathrm{~mL}$ of the extract spotted on the silica gel plate. After separation of triglycerides, PE, and PC, the bands were quantitatively removed to tubes containing heptadecanoic acid (17:0) as an internal standard during the methylation, reextraction, and chromatographic separation of individual fatty acids by gas liquid chromatography. For the purposes of this study, total plasma phospholipid (Fig. 3) was determined by combining the individual quantitative analyses $(\mathrm{mg} / \mathrm{L})$ of fatty acids from plasma PE and PC. These two phospholipids accounted for $>95.0 \%$ of total plasma phospholipids.

Statistical methods. In study 1, plasma and RBC PE and PC, RBC PS, and plasma triglycerides were analyzed for the effects of marine oil supplementation and time (data for RBC PS are not presented) and the interaction of time and supplementation using a repeated measures ANOVA (Tables 3 and 4). The effects of marine oil supplementation, time, and their interaction on RBC and plasma PE (Fig. 1) and PC (Fig. 2) AA, EPA, and DHA ( $\mathrm{g} / 100 \mathrm{~g}$ total fatty acids) were determined by ANOVA. In addition, the effects of time and marine oil supplementation on the concentration of total plasma phospholipid AA and DHA $(\mathrm{mg} / \mathrm{L})$ were determined by ANOVA. Analyses were completed using a Macintosh IIcx and StatView II software (Abacus Concepts, Inc., Berkeley, CA) (26) and software from SAS Institute, Inc. (27) on the mainframe computer at the University of Tennessee, Memphis. In both studies, preplanned comparisons between diet groups and tissues were made using Fisher's least squares difference (28). The effects of packed RBC and several other variables [birth weight, age at enrollment, i.v. lipids (mL), and birth order] on RBC and plasma phospholipid AA and DHA at enrollment were studied by multiple regression. Multiple regression analyses for $\mathrm{AA}$ and $\mathrm{DHA}$ at term also included packed $\mathrm{RBC}(\mathrm{mL})$ administered after enrollment and formula (control or marine oil supplemented). Only 15 infants received $\mathrm{RBC}$ after enrollment.

\section{RESULTS}

Acute Effects of Marine Oil Supplementation on DHA, EPA, and $A A$ (Study 1). There was an interaction between time and marine oil supplementation on RBC and plasma phospholipid DHA. DHA either declined (plasma and RBC PE and PS) or 
EFFECTS OF MARINE OIL-SUPPLEMENTED FORMULAS

Table 3. RBC and plasma phospholipid DHA, EPA, and $A A(\mathrm{~g} / 100 \mathrm{~g})(\text { study } 1)^{*}$

\begin{tabular}{|c|c|c|c|c|c|c|c|c|c|c|c|c|c|c|c|}
\hline & \multicolumn{5}{|c|}{$\mathrm{DHA}(w \mathrm{k}) \dagger$} & \multicolumn{5}{|c|}{ EPA (wk) $\ddagger$} & \multicolumn{5}{|c|}{$\mathrm{AA}(\mathrm{wk}) \S$} \\
\hline & 0 & 1 & 2 & 3 & 4 & 0 & 1 & 2 & 3 & 4 & 0 & 1 & 2 & 3 & 4 \\
\hline \multicolumn{16}{|l|}{ Formula A\| } \\
\hline PC plasma & 1.8 & 1.9 & 1.6 & 1.7 & 1.6 & 0.6 & 0.6 & 0.5 & 0.5 & 0.4 & 9.7 & 9.2 & 8.6 & 8.8 & 8.1 \\
\hline PC RBC & 1.1 & 1.0 & 1.0 & 1.1 & 1.2 & 0.3 & 0.4 & 0.3 & 0.3 & 0.3 & 9.2 & 8.4 & 8.3 & 8.5 & 8.1 \\
\hline PE plasma & 5.2 & 5.5 & 4.8 & 4.9 & 4.2 & 0.5 & 0.6 & 0.7 & 0.5 & 0.5 & 13.7 & 12.8 & 11.9 & 11.8 & 11.6 \\
\hline PE RBC & 6.3 & 6.1 & 6.1 & 5.5 & 5.2 & 0.4 & 0.5 & 0.6 & 0.5 & 0.6 & 23.5 & 24.4 & 25.0 & 22.7 & 22.7 \\
\hline PC plasma & 1.4 & 2.1 & $2.3^{* *}$ & $2.2^{* *}$ & $2.8^{* *}$ & 0.5 & $1.1^{* *}$ & $1.3^{* *}$ & $1.2^{* *}$ & $1.2^{* *}$ & 8.7 & 8.8 & 8.8 & 8.2 & 8.3 \\
\hline PC RBC & 1.2 & 1.2 & 1.4 & $1.6^{* *}$ & $1.8^{* *}$ & 0.4 & $0.7^{* *}$ & $0.8^{* *}$ & $0.9^{* *}$ & $0.7^{* *}$ & 8.9 & 8.3 & 7.7 & 8.0 & 7.7 \\
\hline PE plasma & 5.0 & 7.1 & $7.2^{* *}$ & $7.4^{* *}$ & $7.6^{* *}$ & 0.6 & $2.0^{* *}$ & $2.6^{* *}$ & $2.6^{* *}$ & $3.1^{* *}$ & 13.5 & 13.1 & 13.6 & 11.6 & 11.8 \\
\hline PE RBC & 5.9 & 5.8 & 5.9 & $6.6 * *$ & $6.8 * *$ & 0.5 & 0.8 & $1.0^{* *}$ & $1.4^{* *}$ & $1.5^{* *}$ & 22.5 & $22.2^{* *}$ & $21.9 * *$ & 23.0 & 22.9 \\
\hline \multicolumn{16}{|l|}{ Formula $\mathrm{C} \dagger \dagger$} \\
\hline PC plasma & 1.7 & $2.4^{* *}$ & $2.8^{* *}+\div$ & $2.9^{* *}+t$ & $2.9 * *$ & 0.7 & $2.0^{* *}+\ddagger$ & $2.6^{* *}+\neq$ & $2.6^{* *}+4$ & $2.5^{* *}+\div$ & $10.0 \$$ & 8.4 & $7.6^{* *}$ & $7.5^{* *}$ & $7.2 \ddagger$ \\
\hline PC RBC & 1.1 & $1.6^{* *}$ & $1.7^{* *}$ & $2.0^{* *}$ & $2.2^{* *}$ & 0.4 & $1.1^{* *+7}$ & $1.3^{* *+1}+$ & $1.5^{* *}+7$ & $1.5^{* *}+t$ & 9.1 & 9.4 & 8.3 & $7.1^{* *}$ & 7.8 \\
\hline PE plasma & 6.2 & $8.5^{* *}+\neq$ & $8.7^{* *}$ 扭 & $9.1^{* *}+4$ & $8.7^{* *}$ & 0.7 & $3.7^{* *}+\ddagger$ & $4.0^{* *}+\ddagger$ & $4.2^{* *}+\ddagger$ & $4.6^{* *}+7$ & 14.6 & 12.4 & $10.0 \%$ & 10.6 & $9.1^{* *}+4$ \\
\hline \multicolumn{16}{|l|}{ ANOVA } \\
\hline \multirow[t]{3}{*}{ PC plasma } & \multicolumn{3}{|c|}{ Diet } & \multicolumn{2}{|l|}{$p<0.01$} & \multicolumn{3}{|c|}{ Diet } & \multicolumn{2}{|c|}{$p<0.01$} & \multicolumn{3}{|c|}{ Diet } & \multicolumn{2}{|c|}{$p<0.01$} \\
\hline & & \multicolumn{2}{|c|}{ Time } & \multicolumn{2}{|l|}{$p<0.01$} & \multicolumn{3}{|c|}{ Time } & \multicolumn{2}{|c|}{$p<0.01$} & \multicolumn{3}{|c|}{ Time } & \multicolumn{2}{|c|}{$p<0.01$} \\
\hline & & \multicolumn{2}{|c|}{ Diet $\times$ time } & \multicolumn{2}{|l|}{$p<0.01$} & \multicolumn{3}{|c|}{ Diet $\times$ time } & \multicolumn{2}{|c|}{$p<0.01$} & \multicolumn{3}{|c|}{ Diet $\times$ time } & \multicolumn{2}{|c|}{$p<0.05$} \\
\hline PC RBC & & Diet & & $p<0.01$ & & & Diet & & $p<0$ & & & Diet & & NS & \\
\hline & & Time & & $p<0.01$ & & & Time & & $p<0$ & & & Time & & $p<0$. & \\
\hline & & Diet $x$ & ime & NS & & & Diet $x$ & time & $p<0$ & & & Diet $\times \mathrm{t}$ & ime & NS & \\
\hline PE plasma & & Diet & & $p<0.01$ & & & Diet & & $p<0$ & & & Diet & & $p<0$. & \\
\hline & & Time & & $p<0.01$ & & & Time & & $p<0$ & & & Time & & $p<0$. & \\
\hline & & Diet $x$ & ime & $p<0.01$ & & & Diet $x$ & time & $p<0$ & & & Diet $\times t$ & ime & NS & \\
\hline PE RBC & & Diet & & NS & & & Diet & & $p<0$ & & & Diet & & NS & \\
\hline & & Time & & NS & & & Time & & $p<0$ & & & Time & & $p<0$. & \\
\hline & & Diet $\times$ & ime & $p<0.01$ & & & Diet $x$ & time & $p<0$ & & & Diet $\times t$ & ime & NS & \\
\hline
\end{tabular}

* The analysis included 66 degrees of freedom.

$\dagger$ Fisher's least squares difference SEM plasma PC 0.09, PE 0.50; RBC PC 0.17, PE 0.31.

$\ddagger$ Fisher's least squares difference SEM plasma PC 0.12, PE 0.26; RBC PC 0.05, PE 0.09.

$\S$ Fisher's least squares difference SEM plasma PC 0.40, PE 0.74; RBC PC 0.41, PE 0.76.

$\| n=6$.

I $n=6$.

** Differs from formula A (same time, lipid class, fatty acid), $p<0.01$.

$\dagger \dagger n=5$.

$\ddagger$ Differs from formula $\mathrm{B}, p<0.01$.

was unchanged (plasma and $\mathrm{RBC} P \mathrm{PC}$ ) in unsupplemented infants receiving $3.0 \%$ LLA, whereas it increased in marine oil-supplemented infants (Table 3). Data for PS are not shown because changes were essentially identical to those shown for PE. The mean level of RBC DHA seen in marine oil-supplemented infants was higher than reported after long periods of human milk feeding $(15,16)$, but not higher than found in cord blood (16). The absolute amount of DHA in plasma phospholipids $(\mathrm{mg} / \mathrm{L})$ tended to decline in controls and rise in marine oilsupplemented infants over time, although this did not always reach statistical significance (Table 4).

EPA typically accounted for only 0.4 to $0.7 \%$ of total fatty acids in plasma and RBC phospholipids of control infants. EPA increased 2- to 8-fold in individual lipid classes when the marine oil formulas containing EPA and DHA were fed (Table 3). As might have been expected, a greater increase in EPA occurred in infants fed the higher amount of EPA (formula C). EPA concentrations did not appear to plateau during $4 \mathrm{wk}$ of feeding. Most EPA was found in plasma PC, and there was a highly significant increase in PC EPA $(\mathrm{mg} / \mathrm{L})$ with marine oil supplementation. EPA $(\mathrm{mg} / \mathrm{L})$ also increased significantly in plasma PE and triglycerides (Table 4).

Plasma PE and PC AA (g/100 g total fatty acids) decreased with time and marine oil supplementation (ANOVA, Table 3), but the absolute concentration of AA in plasma $(\mathrm{mg} / \mathrm{L})$ decreased only as a result of time (ANOVA, Table 4). RBC PE and PC AA decreased with time, but further effects of diet were not seen.
Other fatty acids affected by time and/or marine oil supplementation but for which data are not shown included: 1 ) docosapentaenoate $(22: 5 n-3)$ from LLA, which increased minimally but significantly as a result of both marine oil supplementation and time, and 2) docosapentaenoate (22:5n-6) from LOA (18:2n-6), which decreased slightly as a result of both supplementation and time. In general, docosaquatraenoate $(22: 4 n-6)$ was unaffected by time and diet but did increase significantly in RBC PS of control infants compared with those supplemented with marine oil. LOA, LLA, and eicosadienoate $(20: 2 n-6)$ tended to be increased, and the $\Delta^{6}$-desaturation products of LOA (18:3n-6 and $20: 3 n-6)$ tended to be decreased in supplemented compared with control infants.

Long-Term Marine Oil Supplementation: $R B C$ and Plasma Fatty Acids. Changes in AA, EPA, and DHA $(\mathrm{g} / 100 \mathrm{~g}$ total fatty acids). Effects of time, marine oil supplementation, and interactions between time and supplementation were noted for RBC and plasma DHA. Both diet groups had similar PE and plasma PC DHA at enrollment ( $33 \pm 2$ wk PCA). Subsequently, higher amounts of DHA were observed in PE and PC of marine oilsupplemented compared with control infants at all times during the feeding portion of the study ( 38 to 79 wk PCA) (Figs. 1 and 2). Furthermore, DHA remained significantly higher in supplemented infants compared with controls even several months after the feeding portion of the study was completed (93 wk PCA) and infants were consuming a mixed diet with cows' milk.

The patterns of DHA response in the two phospholipid classes 
Table 4. Concentration ( $\mathrm{mg} / \mathrm{L})$ of DHA, EPA, and AA in individual plasma phospholipid and triglyceride*

\begin{tabular}{|c|c|c|c|c|c|c|c|c|c|c|c|c|c|c|c|}
\hline \multirow[b]{2}{*}{ Lipid class } & \multicolumn{5}{|c|}{ DHA (wk) } & \multicolumn{5}{|c|}{ EPA (wk) } & \multicolumn{5}{|c|}{ AA (wk)§ } \\
\hline & 0 & 1 & 2 & 3 & 4 & 0 & 1 & 2 & 3 & 4 & 0 & 1 & 2 & 3 & 4 \\
\hline \multicolumn{16}{|l|}{ Formula $\mathrm{A} \|$} \\
\hline $\mathrm{PC}$ & 3.9 & 3.4 & 3.2 & 2.7 & 2.9 & 4.0 & 3.4 & 2.9 & 2.7 & 2.9 & 60.8 & 50.0 & 47.4 & 44.2 & 51.0 \\
\hline $\mathrm{PE}$ & 2.1 & 1.7 & 1.8 & 1.3 & 1.6 & 0.2 & 0.2 & 0.2 & 0.2 & 0.3 & 5.9 & 3.6 & 4.4 & 3.0 & 3.1 \\
\hline TG & 0.7 & 0.6 & 0.9 & 0.7 & 0.6 & 0.6 & 0.7 & 0.6 & 0.4 & 0.3 & 3.6 & 4.0 & 3.2 & 2.6 & 2.4 \\
\hline \multicolumn{16}{|l|}{ Formula BI } \\
\hline PC & 2.7 & 4.3 & 4.3 & 3.8 & $5.2^{* *}$ & 3.1 & $7.0^{* *}$ & $8.4^{* *}$ & $6.8^{* *}$ & $9.0^{* *}$ & 56.7 & 55.0 & 58.4 & 42.6 & 56.5 \\
\hline $\mathrm{PE}$ & 1.5 & 2.3 & 2.2 & 1.9 & $2.5^{* *}$ & 0.2 & 0.7 & $0.8^{* *}$ & $0.7^{* *}$ & $1.1^{* *}$ & 4.2 & 5.0 & 3.2 & 2.8 & 3.6 \\
\hline TG & 2.0 & $2.2^{* *}$ & $3.8^{* *}$ & $1.5^{* *}$ & $2.4^{* *}$ & 1.2 & $1.5^{* *}$ & $2.5^{* *}$ & $2.0^{* *}$ & $2.2^{* *}$ & 7.4 & 5.5 & 5.8 & 3.2 & 4.2 \\
\hline \multicolumn{16}{|l|}{ Formula $\mathrm{C} \uparrow \dagger$} \\
\hline $\mathrm{PC}$ & 3.9 & $6.3^{* *+1}$ & $5.5^{* *}$ & $4.5^{* *}$ & $6.1^{* *}$ & 4.4 & $13.4^{* *}++$ & $12.8^{* *}+4$ & $14.1^{* *}+\dagger$ & $14.9 * *+\ddagger$ & 62.2 & 51.9 & 45.3 & 40.6 & 43.1 \\
\hline $\mathrm{PE}$ & $2.8 末 t$ & $3.1^{* *}$ & $3.3^{* *}+\frac{1}{4}$ & $2.8^{* *}+千$ & $2.6^{* *}$ & 0.3 & $1.3^{* *+1}$ & $1.2^{* *}$ & $1.2^{* *}+f$ & $1.3^{* *}$ & 6.6 & 4.5 & 3.4 & 3.2 & 2.7 \\
\hline $\mathrm{TG}$ & 0.9 & $3.6^{* *}$ & $3.8^{* *}$ & $2.2^{* *}+\ddagger$ & $3.5^{* *}+4$ & 0.7 & $4.6^{* *}+f$ & $4.5^{* *}+千$ & $2.6^{* *}$ & $2.2^{* *}$ & 5.4 & 6.5 & 3.5 & 2.0 & 2.4 \\
\hline \multicolumn{16}{|l|}{ ANOVA } \\
\hline \multirow[t]{3}{*}{ PC } & \multicolumn{3}{|c|}{ Diet } & \multicolumn{2}{|l|}{$p<0.05$} & \multicolumn{3}{|c|}{ Diet } & \multicolumn{2}{|l|}{$p<0.01$} & \multicolumn{3}{|c|}{ Diet } & \multicolumn{2}{|c|}{ NS } \\
\hline & & \multirow{2}{*}{\multicolumn{2}{|c|}{ Time }} & \multirow{2}{*}{\multicolumn{2}{|c|}{$\begin{array}{l}p<0.05 \\
N S\end{array}$}} & \multicolumn{3}{|c|}{ Time } & \multicolumn{2}{|l|}{$p<0.01$} & \multicolumn{3}{|c|}{ Time } & \multicolumn{2}{|c|}{$p<0.01$} \\
\hline & & & \multirow{2}{*}{ Diet $\times$ time } & NS & & \multicolumn{3}{|c|}{ Diet $\times$ time } & \multicolumn{2}{|l|}{$p<0.01$} & \multicolumn{3}{|c|}{ Diet $\times$ time } & \multicolumn{2}{|c|}{ NS } \\
\hline \multirow[t]{3}{*}{ PE } & & \multirow{2}{*}{\multicolumn{2}{|c|}{$\begin{array}{l}\text { Diet } \\
\text { Time }\end{array}$}} & $p<0.01$ & & & Diet & & $p<0.01$ & & Diet & & & NS & \\
\hline & & & & NS & & & Time & & $p<0.01$ & & Tim & & & $p<0$ & 0.01 \\
\hline & & Diet $x$ & ime & NS & & & Diet $>$ & $x$ time & $p<0.05$ & & Diet & $\times$ time & & NS & \\
\hline TG & & Diet & & $p<0.01$ & & & Diet & & $p<0.01$ & & Diet & & & NS & \\
\hline & & Time & & NS & & & Time & & $p<0.01$ & & Tim & & & $p<0$ & 0.01 \\
\hline & & Diet $x$ & ime & NS & & & Diet $>$ & $x$ time & NS & & Diet & $t \times$ time & & NS & \\
\hline
\end{tabular}

* The analysis included 66 degrees of freedom.

† Fisher's least squares difference SEM PC 0.61, PE 0.32, TG 0.42 .

$\Varangle$ Fisher’s least squares difference SEM PC 1.7, PE 0.19, TG 0.57 .

$\S$ Fisher's least squares difference SEM PC 5.4, PE 0.90, TG 0.92.

$\| n=6$.

I $n=6$.

** Differs from formula A (same time, lipid class, and fatty acid), $p<0.01$.

t† $n=5$.

林 Differs from formula $\mathrm{B}, p<0.01$.

(PE and PC) differed. PE DHA decreased significantly in controls and was maintained (RBC) or increased (plasma) with marine oil supplementation (Fig. $1 C$ and $F$ ). PC DHA remained low and unchanged in controls but rose gradually in both RBC and plasma of marine oil-supplemented infants, reaching a plateau between 48 and 79 wk PCA (Fig. $2 C$ and $F$ ). RBC and plasma PC DHA declined after the feeding portion of the study but were still higher than controls at 93 wk PCA.

RBC and plasma PE (Fig. $I A$ and $D$ ) and PC (Fig. $2 A$ and $D$ ) AA were significantly affected by time and marine oil supplementation (ANOVA). The largest decrease in plasma phospholipid AA and RBC PC AA occurred between enrollment (33 \pm 2 wk PCA) and term ( $38 \pm 2$ wk PCA). AA in marine oilsupplemented compared with control infants was further reduced in RBC and plasma PE (Fig. 1) and PC (Fig. 2) by term. Marine oil-supplemented infants continued to have lower plasma AA than controls throughout infancy (93 wk) (Figs. 1 and 2), even though no infant received marine oil supplementation after 83 wk PCA. Plasma AA began to increase gradually after 57 wk PCA. A more gradual increase in AA late in infancy occurred in infants fed the marine oil-containing formula compared with their controls. RBC PE AA also decreased over time and reached lower levels in marine oil-supplemented infants than in controls. The decreases in RBC PE AA were much more gradual than in plasma phospholipids (PE and PC) and in RBC PC, however, and reached a nadir later in marine oil-supplemented infants ( $\sim 68$ wk PCA). AA returned to enrollment levels (Figs. $1 A$ and $D, 2 A$ and $D$, and $3 A$ ) only after most infants were eating a mixed diet and drinking whole cows' milk instead of formula.

RBC and plasma PE EPA in control infants remained low throughout the period of study, rising slightly at 93 wk PCA (Fig. $1 B$ and $E$ ). In PC, EPA declined between enrollment and term, remained low throughout infancy, and also increased slightly at
93 wk. In contrast, EPA increased over time in RBC and plasma phospholipids of marine oil-supplemented infants, reaching a maximum at $57 \mathrm{wk}$ in $\mathrm{PC}$ (Fig. $2 B$ and $E$ ) and $68 \mathrm{wk}$ in PE (Fig. $1 B$ and $E$ ).

Because preterm infants have quite variable neonatal/perinatal histories and exposures to factors that could influence phospholipid fatty acids (such as i.v. lipids and packed RBC), we determined the extent to which these factors were related to the AA and DHA at enrollment and term (Table 5). Age at enrollment and i.v. lipids (Intralipid; KabiVitrum Inc., Clayton, NC) were the factors most likely to influence AA and DHA at enrollment. Age at enrollment was associated with lower AA and DHA. Intralipid was associated with lower AA. At term, n-3 supplementation accounted for 40 to $55 \%$ of the variance in plasma and RBC DHA (positively related) and 10 to $21 \%$ of the variance in AA (negatively related). Minor effects of packed RBC were seen on RBC PE DHA at term, with the quantity before enrollment having a small negative effect and the quantity after enrollment a small positive effect.

Changes in $A A$ and DHA $(m g / L)$. The effects of time and marine oil supplementation on the quantity of AA and DHA in plasma phospholipids are shown in Figure $3 A$ and $B$. Time and marine oil supplementation significantly affected both fatty acids $(p<0.001)$. When infants fed the control preterm and term formulas (formula A followed by formula $\mathrm{A}-\mathrm{T}$ ) were compared with those fed a low level of marine oil supplementation (formula $B$ followed by formula B-T), those receiving marine oil had significantly more plasma phospholipid DHA at all times after enrollment (Fig. 3B). Plasma DHA in supplemented infants continued to rise over a 2 -mo period and then remained high throughout the period of marine oil supplementation (to $79 \mathrm{wk}$ postconception) (Fig. $3 B$ ). DHA was still elevated in experimen- 

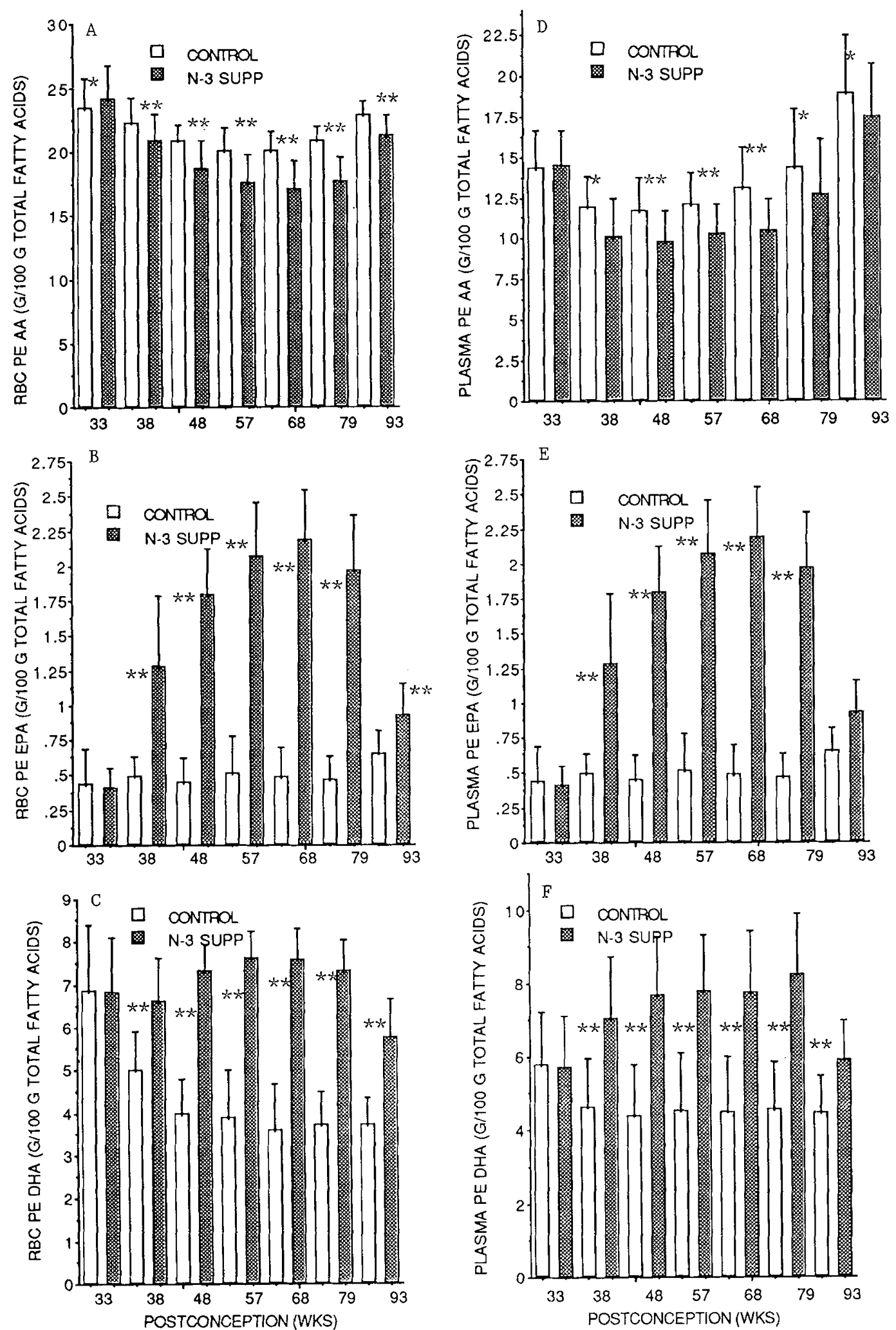

Fig. 1. The effect of time and extended feeding of marine oil-supplemented formula on RBC and plasma PE AA, EPA, and DHA (g/100 g total fatty acids) (mean $\pm \mathrm{SD}$ ). ANOVA: time, $p<0.001$; marine oil supplementation, $p<0.001$; marine oil supplementation by time, $p<0.001$ except plasma PE AA, $p<0.05$. Infants fed formula A and A-T (CONTROL) vs infants fed formula B and B-T $(N-3 S U P P):{ }^{*} p<0.05 ;{ }^{* *} p<0.001$ using Fisher's least squares difference (28).

tal compared with control infants at 93 wk PCA, 2-3 mo after marine oil was removed from the diet.

Plasma phospholipid AA (mg/L) decreased significantly between enrollment and term regardless of the formula fed (Fig. $3 A$ ). Furthermore, the concentration of $\mathrm{AA}$ in plasma remained lower than enrollment throughout the feeding period (through
79 wk PCA). The mean concentration of AA did begin to increase gradually during the last half of infancy, but the higher concentrations of AA seen at enrollment were not reached again until 93 wk PCA. Beginning at term and continuing through $79 \mathrm{wk}$ PCA the quantity of plasma AA was significantly lower in infants receiving the marine oil supplement compared with controls. 

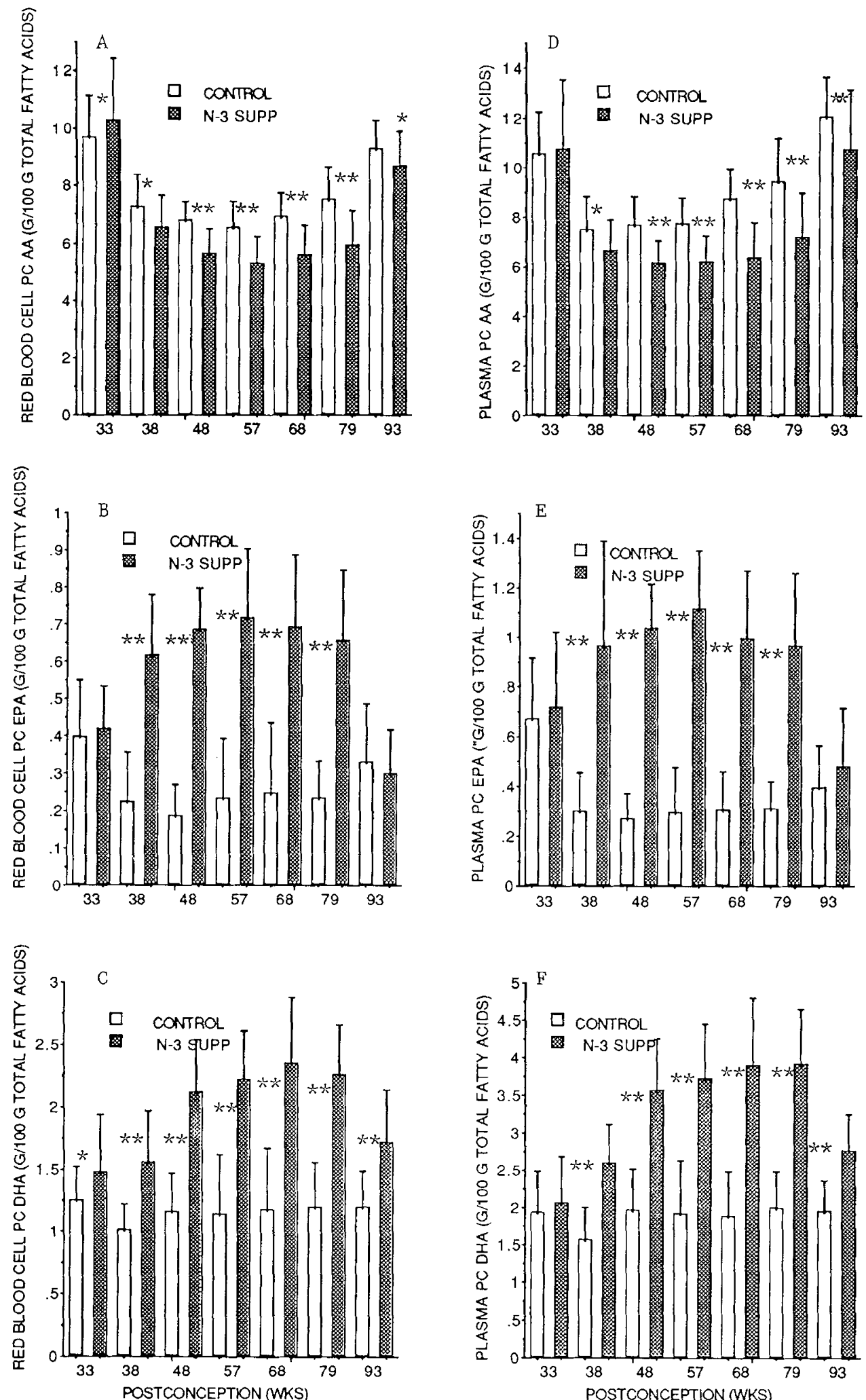

Fig. 2. The effect of time and extended feeding of marine oil-supplemented formula on RBC and plasma PC AA, EPA, and DHA ( $\mathrm{g} / 100 \mathrm{~g}$ total fatty acids) (mean $\pm \mathrm{SD}$ ). ANOVA: time, $p<0.001$; marine oil supplementation, $p<0.001$; marine oil supplementation by time, $p<0.001$. Infants fed formula A and A-T (CONTROL) vs infants fed formula B and B-T $\left(N-3\right.$ SUPP): ${ }^{*} p<0.05 ;{ }^{* *} p<0.001$ using Fisher's least squares difference $(28)$.

Because the gradual rise in AA during the study period did not occur until very late in supplemented infants and was of smaller magnitude than seen in controls, the difference in AA between groups became larger over time.

\section{DISCUSSION}

These studies demonstrate conclusively that even large amounts of LLA do not prevent declines in RBC and plasma 

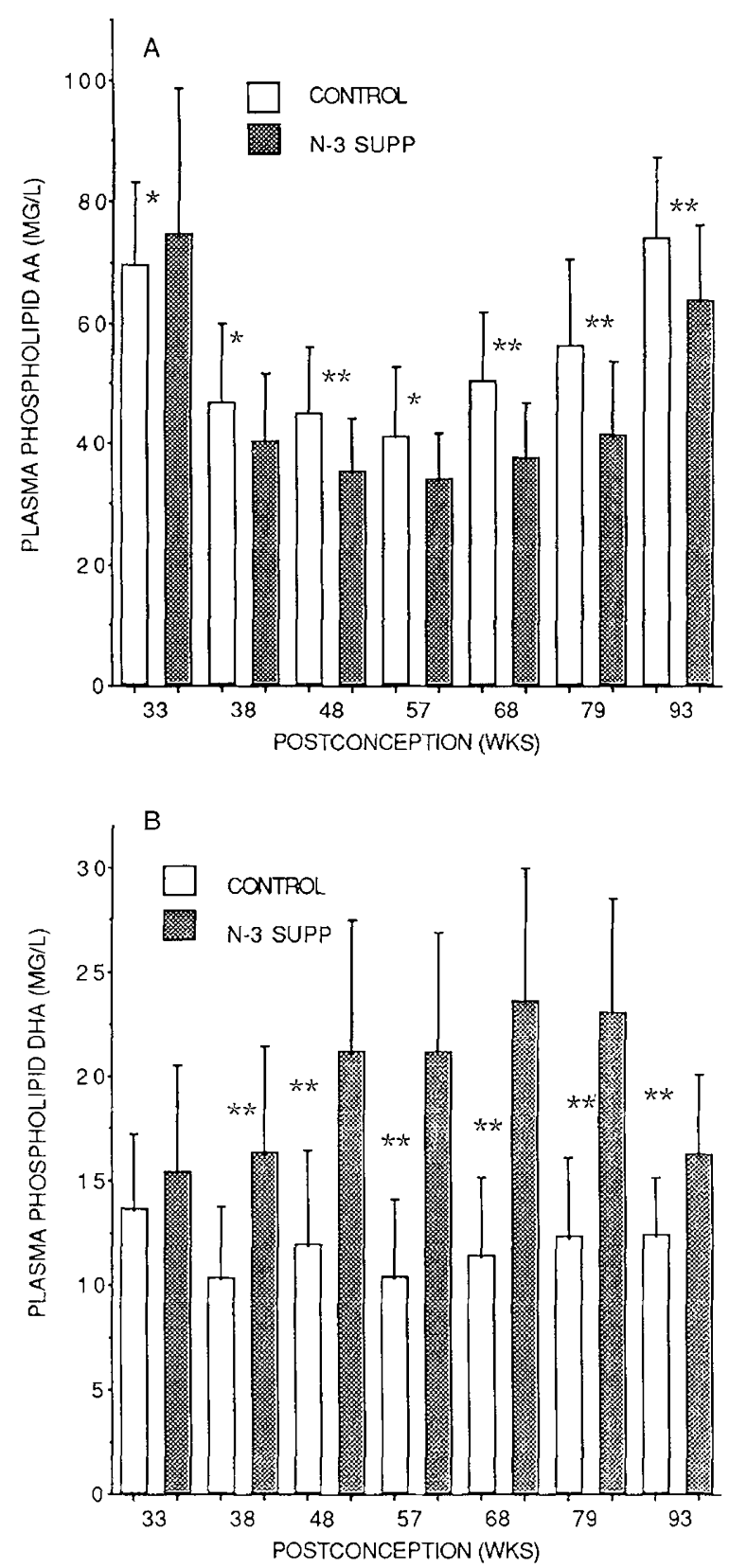

Fig. 3. The effect of time and marine oil supplementation on plasma phospholipid $(\mathrm{PC}+\mathrm{PE})$ fatty acids $(\mathrm{mg} / \mathrm{L})($ mean $\pm \mathrm{SD}): A, \mathrm{AA} ; B$, DHA. ANOVA: time, $p<0.001$; marine oil supplementation, $p<0.001$; marine oil supplementation by time, $p<0.001$. Infants fed formula $A$ followed by formula A-T (CONTROL) vs infants fed formula B followed by formula B-T $(N-3 S U P P):{ }^{*} p<0.05 ;{ }^{*} p<0.001$ using Fisher's least squares difference (28).

phospholipid DHA in VLBW infants. Moreover, RBC PE DHA levels at term were below those typically seen in infants born at term (16), suggesting that DHA status was less than optimal throughout the last trimester. At enrollment, plasma phospholipid DHA was $2.0 \%$ compared with $2.5 \%$ reported for n-3 deficient monkeys at birth (1), suggesting that DHA status of VLBW infants is at least as poor as $\mathrm{n}-3$ deficient monkeys at birth. Unlike monkeys deprived of LLA, however, these preterm infants fed LLA did not experience continued postnatal declines in plasma phospholipid DHA to extremely low levels, evidence that LLA is converted to DHA to some degree. Declines in RBC DHA followed those in plasma phospholipids, but the two compartments did equilibrate eventually. The lower levels of DHA found in RBC PE of these infants compared with those previously
Table 5. RBC and plasma PE and PC DHA and $A A$ at 33 (enrollment) and 38 (term) wk postconception: multiple regression analysis of neonatal and perinatal factors

\begin{tabular}{|c|c|c|c|c|c|}
\hline Tissue & $\begin{array}{c}\text { Phospho- } \\
\text { lipid }\end{array}$ & $\begin{array}{l}\text { PCA } \\
\text { (wk) }\end{array}$ & Fatty acid & Variable* & $\begin{array}{c}\text { Cumulative } \\
r^{2}\end{array}$ \\
\hline \multirow[t]{15}{*}{$\mathrm{RBC}$} & \multirow[t]{9}{*}{ PE } & \multirow[t]{3}{*}{$33 \dagger$} & \multirow[t]{2}{*}{$\mathrm{AA}$} & Age at start $(-)$ & 0.28 \\
\hline & & & & Intralipid (-) & 0.34 \\
\hline & & & DHA & Age at start $(-)$ & 0.22 \\
\hline & & \multirow[t]{6}{*}{$38 \$$} & \multirow[t]{2}{*}{$\mathrm{AA}$} & $\mathrm{n}-3 \operatorname{supp}(-)$ & 0.13 \\
\hline & & & & Age at start $(-)$ & 0.16 \\
\hline & & & \multirow[t]{4}{*}{ DHA } & $n-3 \operatorname{supp}(+)$ & 0.43 \\
\hline & & & & Parity (-) & 0.47 \\
\hline & & & & RBC poststart $(-)$ & 0.51 \\
\hline & & & & RBC prestart (+) & 0.54 \\
\hline & \multirow[t]{6}{*}{ PC } & \multirow[t]{3}{*}{33} & \multirow[t]{2}{*}{ AA } & Age at start $(-)$ & 0.14 \\
\hline & & & & Intralipid (-) & 0.17 \\
\hline & & & DHA & None significant & \\
\hline & & \multirow[t]{3}{*}{38} & \multirow[t]{2}{*}{$\mathrm{AA}$} & $\mathrm{n}-3 \operatorname{supp}(-)$ & 0.13 \\
\hline & & & & Birth wt $(+)$ & 0.20 \\
\hline & & & DHA & $n-3 \operatorname{supp}(+)$ & 0.43 \\
\hline \multirow[t]{10}{*}{ Plasma } & \multirow[t]{5}{*}{$\mathrm{PE}$} & \multirow[t]{3}{*}{33} & \multirow[t]{2}{*}{$\mathrm{AA}$} & Age at start $(-)$ & 0.04 \\
\hline & & & & Birth wt $(-)$ & 0.12 \\
\hline & & & DHA & None significant & \\
\hline & & \multirow[t]{2}{*}{38} & $\mathrm{AA}$ & $n-3 \operatorname{supp}(-)$ & 0.21 \\
\hline & & & DHA & $\mathrm{n}-3 \operatorname{supp}(+)$ & 0.40 \\
\hline & \multirow[t]{5}{*}{ PC } & \multirow[t]{2}{*}{33} & AA & None significant & \\
\hline & & & DHA & None significant & \\
\hline & & \multirow[t]{3}{*}{38} & AA & $\mathrm{n}-3 \operatorname{supp}(-)$ & 0.10 \\
\hline & & & & RBC poststart (-) & 0.15 \\
\hline & & & DHA & $\mathrm{n}-3 \operatorname{supp}(+)$ & 0.55 \\
\hline
\end{tabular}

* The sign in parentheses designates whether the relationship is positive $(+)$ or negative $(-)$ effect.

$\dagger$ The variables included at $33 \mathrm{wk}$ were age at enroliment, birth wt, Intralipid $(\mathrm{mL})$ administered before enrollment, packed $\mathrm{RBC}(\mathrm{mL})$ administered before enrollment (RBC prestart), and birth order.

$\ddagger R B C(\mathrm{~mL})$ administered after enrollment (RBC poststart) and formula assignment [control or marine oil $(\mathrm{n}-3)$ supplemented] were included in analysis at $38 \mathrm{wk}$.

reported in cord blood (16) and after human milk feeding (15, 16) suggest that VLBW infants do not generate DHA from LLA at optimal rates.

Preformed 20- and 22-carbon fatty acids accumulate in membranes more avidly than their 18-carbon precursors (29). During marine oil supplementation, RBC PE DHA plateaued in these infants at 7.0 to $8.0 \%$ of total fatty acids; i.e. in the range found in RBC of cord blood (16) and in breast-fed term infants (15) and twice as high as in controls fed 5.0\% LLA. Moreover, those fed the experimental, marine oil-supplemented formula to $57 \mathrm{wk}$ postconception had improved visual acuity [Teller acuity card procedure (30)] compared with control infants (31), suggesting that retinal/neural function was optimized by marine oil supplementation. Uauy et al. (32) also reported improved visual evoked potential acuity at $57 \mathrm{wk}$ in VLBW infants fed different marine oil-supplemented and control formulas to $57 \mathrm{wk}$.

Infants did not receive dietary AA in the first 6 mo of life, and $\mathrm{RBC}$ and phospholipid AA declined continuously during this period. The declines in plasma phospholipid AA were consistent with reduced AA synthesis because decreases in RBC phosphlipid AA occurred after those in plasma phospholipids. The decline in AA over time could be due in part to consumption of large amounts of LOA in formula, inasmuch as plasma phospholipid AA was shown to decrease in adults (33) and term infants (34) consuming $>5.0-7.0 \%$ of energy from LOA. However, identical amounts of AA were found in $\mathrm{RBC}$ phospholipids of term infants fed formulas with 7.0 and $22.0 \%$ of energy from LOA for many months (15), suggesting that some mechanism other than high 
LOA intake or in concert with high LOA intakes is responsible for the decline in AA seen in these preterm infants.

Extended feeding of marine oil-supplemented formula reduced $\mathrm{RBC}$ and plasma phospholipid AA over and above the reductions seen with time. EPA in phospholipids rose during the same period. Whether lower RBC and plasma AA in marine oil-fed infants reflect a further reduction in AA synthesis or merely the substitution of dietary EPA for AA in phospholipids cannot be determined from these data. During the acute feeding trial, plasma phospholipid AA was reduced significantly. We did not find any effect of marine oil on RBC phospholipid AA, but the reduction in plasma phospholipid $\mathrm{AA}$ is evidence that decreases would have occurred had feeding of marine oil-supplemented preterm formula been continued.

AA rose in the second half of infancy, but the increase in plasma phospholipid AA did not appear to be related to maturation of elongation/desaturation of 18-carbon fatty acids, inasmuch as phospholipid DHA did not increase at any time during infancy. The slight upward trend in plasma phospholipid AA beginning around 7 mo coincided with the inclusion of energy from eggs and meat, both dietary sources of AA. We have reported that the number of servings of eggs and meat positively influenced plasma phospholipid AA, accounting for 10.0 and $15.0 \%$ of the variance in AA at 79 and $93 \mathrm{wk}$, respectively (35).

We anticipated that feeding of very long chain n-3 fatty acids would diminish AA status to some degree. However, our early, extended studies of term infants (15) did not lead us to anticipate a fall in RBC and plasma AA in the absence of marine oil supplementation or an association between diminished AA status and poorer growth $(36,37)$ and cognition $(38)$. Although we (31) and others (32) have reported associated improvements in visual acuity with marine oil supplementation of formula, the optimal period of n-3 supplementation is not known. Studies in which visual acuity has been improved have involved marine oil supplementation until at least $57 \mathrm{wk}$ postconception $(31,32)$. These studies demonstrate that supplementation of this duration with low levels of EPA and DHA ( $0.25 \%$ of energy) decreases RBC and plasma phospholipid AA. Shorter feeding trials, DHA-containing formulas free of EPA, and formulas including AA need to be considered. These studies will need to monitor biochemistry, growth, cognition, and visual or retinal development. The ultimate goal should be to improve DHA status without creating potentially more serious deficits in AA status.

\section{REFERENCES}

1. Neuringer M, Conner WE, Van Petten C, Barstad L 1984 Dietary omega-3 fatty acid deficiency and visual loss in infant rhesus monkeys. J Clin Invest 73:272-276

2. Benolken RM, Anderson RE, Wheeler TG 1973 Membrane fatty acids associated with the electrical response in visual excitation. Science 182:12531254

3. Wheeler TG, Benolken RM, Anderson RE 1975 Visual membranes: specificity of fatty acid precursors for the electrical response to illumination. Science 188:1312-1314

4. Neuringer M, Conner WE, Luck SL 1985 Omega-3 fatty acid deficiency in rhesus monkeys: depletion of retinal docosahexaenoic acid and abnormal electroretinograms. Am J Clin Nutr 43:706

5. Neuringer M, Conner WE, Luck SJ 1985 Suppression of ERG-amplitude of repetitive stimulation in rhesus monkeys deficient in retinal docosahexaenoic acid. Invest Ophthalmol Vis Sci 26(suppl 3):31(abstr)

6. Neuringer M, Conner WE, Daigle D, Barstad L 1988 Electroretinogram abnormalities in young rhesus monkeys deprived of omega- 3 fatty acids during gestation and postnatal development or only postnatally. Invest Ophthalmol Vis Sci 29(suppl 3):145(abstr)

7. Lamptey MS, Walker BL 1976 A possible essential role for dietary linolenic acid in the development of the young rat. J Nutr 106:86-93

8. Yamamoto N, Saitoh M, Moriuchi A, Nomura M, Okuyama H 1987 Effect of dietary alpha linolenate/linoleate balance on brain lipid compositions and learning ability in rats. J Lipid Res 28: 144-151

9. Enslen M. Nouvelot A, Milon H 1987 Effects of $n-3$ polyunsaturated fatty acid deficiency during development in the rat: functional effects. In: Lands WEM (ed) Proceedings of the AOCS Short Course on Polyunsaturated Fatty Acids and Eicosanoids. American Oil Chemists' Society, Champaign, IL, pp 495 497
10. Clandinin MT, Chappell JE, Leong S, Heim T, Swyer PR, Chance GW 1980 Intrauterine fatty acid accretion rates in human brain: implications for fatty acid requirements. Early Hum Dev 4:121-129

11. Martinez M, Ballabriga A 1987 Effect of parenteral nutrition with high doses of linoleate on the developing human liver and brain. Lipids 22:133-138

12. Martinez M, Ballabriga A, Gil-Gibernou JJ 1988 Lipids of the developing human retina: I. Total fatty acids, plasmalogens, and fatty acid composition of ethanolamine and choline phosphoglycerides. J Neurosci Res 20:484-490

13. Sanders TAB, Ellis FR, Dickerson JWT 1978 Studies of vegans: the fatty acid composition of plasma phosphoglycerides, erythrocytes, adipose tissue and breast milk and some indications to susceptibility to ischemic heart disease in vegans and omnivores. Am I Clin Nutr 31:805-813

14. Sanders TAB, Naismith DJ 1979 A comparison of the influence of breastfeeding and bottle-feeding on the fatty acid composition of the erythrocytes. Br J Nutr 41:619-623

15. Putnam JC, Carlson SE, DeVoe PW, Barness LA 1982 The effect of vaniations in dietary fatty acids on the fatty acid composition of erythrocyte phosphatidylcholine and phosphatidylethanolamine in human infants. Am J Clin Nutr 36:106-114

16. Carlson SE, Rhodes PG, Ferguson MG 1986 Docosahexaenoic acid status of preterm infants at birth and following feeding with human milk or formula. Am J Clin Nutr 45:798-804

17. Carlson SE, Rhodes PG, Rao VS, Goldgar DE 1987 Effect of fish oil supplementation on the omega- 3 fatty acid content of red blood cell membranes in preterm infants. Pediatr Res 21:507-510

18. Liu C-CF, Carlson SE, Rhodes PG, Rao VS, Meydrech EF 1987 Increase in plasma phospholipid docosahexaenoic and eicosapentaenoic acids as a reflection of their intake and mode of administration. Pediatr Res 22:292-296

19. Innis SM, Foote KD, MacKinnon MJ, King DJ 1990 Plasma and red blood cell fatty acids of low birthweight infants fed their mother's expressed breast milk or preterm infant formula. Am $J$ Clin Nutr 51:994-1000

20. Uauy RD, Birch DG, Birch EE, Tyson JE, Hoffman DR 1990 Effect of dietary omega- 3 fatty acids on retinal function of very-low-birth-weight neonates. Pediatr Res 28:485-492

21. Dodge JT, Phillips GB 1967 Composition of phospholipids and phospholipid fatty acids and aldehyde in human red cells. J Lipid Res 8:667-675

22. Folch J, Lees M, Stanley GHS 1957 A simple method for the isolation and purification of total lipids from animal tissues. J Biol Chem 226:497-509

23. Zail SS, Pickering A 1979 Fatty acid composition of erythrocytes in hereditary spherocytosis. Br J Haematol 43:399-402

24. Malins DC, Mangold HK 1960 Analysis of complex lipid mixtures by thinlayer chromatography and complementary methods. J Am Oil Chem Soc 37:576-578

25. Morrison WR, Smith LM 1964 Preparation of fatty acid methyl esters and dimethylacetals. J Lipid Res 5:600-608

26. Feldman DS, Hofmann R, Gagnon J, Simpson J 1984 StatView II: The Solution for Data Analysis and Presentation Graphics. Abacus Concepts, Berkeley, CA

27. SAS Institute, Inc 1985 SAS User's Guide: Statistics, Version 5 ed. SAS Institute, Inc, Cary, NC, p 956

28. Sokol RR, Rohlf FJ 1981 Biometry, 2nd ed. WH Freeman, New York, pp 232-262

29. Sinclair AJ, Crawford MA 1972 The incorporation of linolenic acid and docosahexaenoic acid in liver and brain lipids of developing rats. FEBS Lett 26:127-129

30. McDonald M, Dobson V, Sebris SL, Baitch L, Varner D, Teller DY 1985 The acuity card procedure: a rapid test of infant acuity. Invest Ophthalmol Vis Sci 26:1158-1162

31. Carlson S, Cooke R, Werkman S, Peeples J 1989 Docosahexaenoate (DHA) and eicosapentaenoate (EPA) supplementation of preterm infants: effects on phospholipid DHA and visual acuity. FASEB J 3:A 1056 (abstr)

32. Uauy R, Birch D, Birch E, Hoffman DR 1991 Effect of dietary omega-3 fatty acids (FA) on eye and brain development in very low birth weight neonates (VLBWN). In: Health Effects of Omega-3 Polyunsaturated Fatty Acids in Seafoods, World Review of Nutrition and Dietetics. Karger Publishing Press, Basel, Switzerland, pp 506-507

33. Lasserre M, Mendy F, Spielmann D, Jacotot B 1985 Effects of different dietary intake of essential fatty acids on $C 20: 3 \omega 6$ and $C 20: 4 \omega 6$ serum levels in human adults. Lipids 20:227-233

34. Hansen AE, Wiese HF, Adam DJD, Boelsche AN, Haggard ME, Davis H, Newsom WT, Pesut L 1964 Influence of diet on blood serum lipids in pregnant women and newborn infants. Am J Clin Nutr 15:11-19

35. Carlson SE, Peeples JM, Werkman SH, Cooke RJ, Wilson III WM 1991 Arachidonic acid (AA) in plasma and red blood cell (RBC) phospholipids (PL) during followup of preterm infants: occurrence, dietary determinants and functional relationships. In: Health Effects of Omega-3 Polyunsaturated Fatty Acids in Seafoods, World Review of Nutrition and Dietetics. Karger Publishing Press, Basel, Switzerland, p 507

36. Cooke RJ, Carlson SE, Werkman SH, Peeples JM 1991 Growth of premature infants in year one: effect of marine oil supplementation of formula. FASEB J 5:A 1072(abstr)

37. Carlson SE, Cooke RJ, Werkman SH, Tolley EA 1992 First year growth of preterm infants fed standard compared to marine oil (n-3) supplemented formulas. Lipids (in press)

38. Carlson SE, Peeples JM, Werkman SH, Cooke RJ, Wilson WM 1991 Plasma phosphatidylcholine (PC) arachidonate (AA) concentrations of preterm (PT) infants during infancy: growth and development. FASEB J 5:A1320(abstr) 